\title{
Research on Performance Commitment Agreement of Continuous M\&A of Advertising Media Enterprises in China
} A Case Study of Continuous M\&A of Lianjian Optoelectronics

\author{
Liangchen Zhang ${ }^{1} \mathrm{Yu} \mathrm{Wu}{ }^{1, *}$ Chao Chen $^{1}$ \\ ${ }^{1}$ School of Accounting, Xinhua College of Sun Yat-sen University, Dongguan, Guangdong 523133, China \\ *Corresponding author.Email:66267567@qq.com
}

\begin{abstract}
Due to the rapid development of advertising media industry, traditional media enterprises have to adopt M\&A (mergers and acquisitions) to keep up with the speed of industry development. However, M\&A, especially in a short period of time, is often accompanied by uncertain risks such as information asymmetry and difficult to predict future profits. Therefore, in order to avoid uncertainty risk, performance commitment agreement began to be widely used in media mergers and acquisitions. This paper takes the application case of Lianjian Optoelectronics to performance commitment agreement in continuous M\&A, starting with short-term and shortterm performance analysis, performance commitment standard and original country. The purpose of this paper is to study the long-term and short-term impact of M\&A application performance commitment agreement on company performance. The case study found that different performance compensation methods will have different effects on M\&A risk, and the performance commitment agreement will greatly improve the long-term operating risk of the company.
\end{abstract}

Keywords: Advertising media, M\&A, Performance Commitment agreement, Lianjian optoelectronics.

\section{INTRODUCTION}

\subsection{Background and Significance of the Study}

According to the Internet Development Statistics report, as of June 2020, the number of Internet users using mobile phones in China is 932 million out of 940 million total internet users. The rapid development of mobile Internet in recent years has made the market share and role of online advertising, especially mobile advertising, more and more large, prompting many traditional media enterprises to urgently seek transformation and change.

Due to the demand for rapid transformation and expansion, some enterprises will prefer to choose just M\&A, while others will choose the radical continuous M\&A to meet the needs of the strategic layout. Since M\&A is often accompanied by uncertainty risks, the market gradually introduces the performance commitment system. However, the performance commitment agreement is also a double-edged sword. To complete the performance of the agreement, the management of the acquired party may have shortsighted business behaviour or even false performance.

Combined with continuous M\&A and performance commitment, this paper selects the application case of Lianjian Optoelectronics in continuous M\&A. This paper studies the impact of M\&A on corporate performance during and after the performance commitment period, and probes into the performance commitment of the acquired party and the reasons, and further analyzes its operating condition.

The purpose of this paper is to provide reference and practical significance for the use of performance commitment agreement in M\&A transactions of listed companies in the media advertising industry and to provide more abundant 
ideas for the study of continuous M\&A and performance commitment of listed companies.

\subsection{Literature Review}

\subsubsection{International Research Status}

Performance commitment agreement originated from a mechanism of capital market in the last century - or consideration (Earnout). The deferred payment method adopted is essentially a mechanism of risk distribution. Solving the risk of target enterprise valuation caused by information asymmetry is the fundamental purpose of its birth.

Christian Tallau (2009) of this paper proposes an evaluation model of contingent claims related to contingent consideration. This is based on option pricing theory which can effectively bridge the possible losses caused by the information gap between buyers and sellers in a simple way. Reena Kohli (2015) believes that in the three conventional payment methods, compared with cash and stock payment, contingent consideration is the best way to avoid the adverse selection risk of the acquirer.

\subsubsection{China Research Status}

Although the performance commitment agreement originated from the western contingent consideration, it is most widely used in China in the introduction of the developed gambling agreement.

Yuexiang Wang and Junxin Yang (2014) believe that the performance commitment agreement is not equivalent to the gambling agreement, and the signing of the gambling agreement is a market-oriented game behavior for both parties. A performance commitment agreement has regulatory means to protect the interests of minority shareholders. Huijie Liu (2016) found that the overall impact of gambling agreements on corporate performance is not significant, and in the financing market is not perfect in the Chinese institutional environment due to the ways and means for investors to take advantage of their position to obtain higher returns for enterprises or themselves. Xiangqiang Liu (2018) also found that earnings management has a partial intermediary effect on M\&A performance commitment and audit fees, that is, performance commitment will lead to earnings management by the promise party, and then increase audit costs.

\subsubsection{Literature Review}

In the process of combing the relevant literature, it is found that the research direction of foreign scholars is more open to the operation mechanism, improvement of consideration and the evaluation of performance commitment agreement tends to be positive. Due to the stage of economic transformation, the corresponding legal and system guarantees are not clear, so the attitude towards performance commitment agreement is cautious and critical. The research direction points to the risks for the motivation of gambling agreement.

Synthesizing the above literature summary, it can be seen that the domestic-related system is still in the perfecting stage and from the rational evaluation and analysis of the impact of performance commitment agreement on M\&A, it is uncertain if it has any practical significance.

\section{THEORETICAL ANALYSIS}

\subsection{Definition of Relevant Concepts}

\subsubsection{Contingent Consideration and Valuation Adjustment Mechanisms}

Earn-out mechanism is a special pricing and deferred payment mechanism, which originates from the M\&A transaction process in the capital market and usually appears as an important clause in $\mathrm{M} \& \mathrm{~A}$ contracts. If there is a consideration mechanism designed a special payment arrangement model, the investor will pay the agreed payment price in installments and can agree with the company receiving the investment a "profitability observation period" aaccording to the financier's earnings performance before the end of the agreed time. The mechanism is essentially a deferred risk-sharing mechanism.

The valuation adjustment mechanism occurs on a new product after introducing the contingent consideration mechanism into the country. Although the scenario and the target object are essentially the same, the valuation adjustment mechanism adds compensation clauses in addition to the investor's deferred payment. Due to the imperfection of the domestic investment environment and the lack of due diligence, the investors know little about the actual situation of the financing party and are unable to accurately estimate the value of the target enterprise and the investment cost. To avoid misjudgment of investments, investors add a compensation 
mechanism to the agreement. However, the newly added compensation mechanism has an obligation to both parties and is carried out around a subject matter, so it is vividly called the "gambling agreement" which reflects that the essence of the valuation adjustment mechanism has deviated from the initial deferred payment mechanism. It becomes a profit-making capital game between investors and financiers, and loses its original purpose.

\subsubsection{Performance Commitment Agreement and Gambling Agreement}

Performance commitment agreement comes from contingent consideration mechanism and is commonly used in M\&A transactions. The gambling agreement is a popular saying - its formal name should be "valuation adjustment mechanism". There are obvious differences in definition and form between performance commitment agreement and gambling agreement, but in many practical cases in China, performance commitment is often used as the gambling agreement, and the boundary between them becomes more and more blurred. Under the domestic system, a performance commitment agreement also has two-way performance commitment or substandard compensation measures. Therefore, in the subsequent discussions of this paper, the performance commitment agreement will also be extended to the category of gambling agreement and will compare the agreements to which is more suitable for the national conditions.

\subsection{The Theoretical Basis for the Application of Performance Commitments in Successive Mergers and Acquisitions}

\subsubsection{Real Option Theory}

An option is a right without a related symmetrical obligation, that is, the option to buy or sell agreed on assets at or before the maturity date at a predetermined price. The purpose of the performance commitment agreement and the real option is similar - they are at the expense of the future development of the enterprise uncertainty control. Performance commitment agreement can be regarded as a special application of real-option in a specific economic environment. Investors take equity allocation and investment cost as the cost in exchange for avoiding the option of financing enterprises in the future development risk.

\subsubsection{Information Asymmetric Theory}

Information asymmetry theory is a common economic theory, which mainly studies the market transaction behavior and market operation efficiency caused by the imbalance of information resources. According to the theory of information asymmetry, the existence of prior information asymmetry in M\&A transactions is due to the preciseness of domestic due diligence and the deliberate concealment of the management of the acquired enterprise. This leads to investors who may mistakenly estimate the actual value of the acquired party and make the investment M\&A cost wrongly. However, the hindsight information may exist at the same time, because the interests of the acquired party and the acquirer are not exactly the same, and the management of the acquired party may be cash out of the market or ignore the development of the enterprise. As a result, the development prospects of the acquired enterprises are contrary to expectations.

\subsubsection{Incentive Theory}

Incentive theory is the theory of how to arouse the enthusiasm of people. For enterprise governance and trading behavior, incentive theory often applies contract governance. Through appropriate incentives or necessary penalties, it can effectively avoid the risk of uncertainty. Protect the rights and interests of all parties. We can find that the performance commitment agreement is the practical application of the contract incentive theory, especially the gambling agreement which adds the compensation clause, which fully embodies the clause measures of reward and punishment to both parties in the contract governance.

\section{ANALYSIS OF M\&A IN ADVERTISING MEDIA INDUSTRY}

\subsection{Current Situation and Characteristics of M\&A in China's Advertising Media Industry}

According to the China Advertising Marketing Industry Capital report, there were 1164 financing cases in China's advertising marketing industry in 2009-2019, and 629 enterprises attracted as much as 61.8 billion yuan in the decade. 


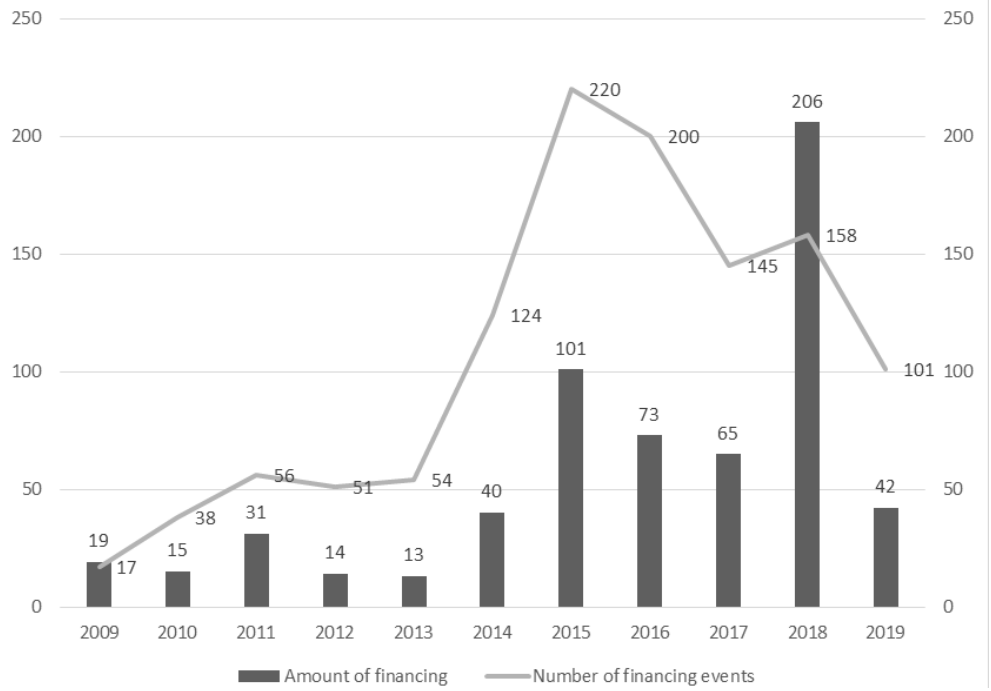

Figure 1 Financing of China's Advertising Marketing Industry, 2009-2019.

The report shows that 2009-2013 is a period of relatively flat industry financing growth, 2014 began to enter a high growth stage and the industry reached its peak in 2015. Combining with the peak period of M\&A and the development of the advertising media industry, it can be found that most of the frequent M\&A in the advertising media industry in recent years is due to strategic considerations. On the other hand, with the rapid development of the digital advertising business, traditional advertising enterprises need to change the traditional media resource agent mode, explore the way of cooperation with new media, and build digital marketing agents.

\subsection{The Performance Commitments of China's Advertising Media Industry Are Up to Standard}

According to China reporting Network statistics, between 2013 and 2019, the advertising media sector's new growth in performance commitments rose overall and reached a peak of 86 orders in recent years in 2015 . It can be seen that the stakes for both sides of the M\&A deal are increasing.

A study released by China reporting Network shows that from 2013 to 2017 , a total of 59 M\&A transactions ended the performance commitment period, 40 of which reached the performance commitment target, accounting for $72.73 \%$. Advertising media sector performance commitments are basically in a healthy and stable state, part of the performance commitments can be achieved beyond expectations.

\section{A CASE STUDY OF CONTINUOUS M\&A OF LIANJIAN OPTOELECTRONICS}

\subsection{Case Company Profile}

\subsubsection{Merger Profile}

Shenzhen Lianjian Optoelectronic Co., Ltd. (hereinafter referred to as "Lianjian Optoelectronics ") was listed on the Shenzhen Stock Exchange gem in 2011. The company's business scope covers LED (L ED) display rental sales, electronic product technology development, system integration and advertising business. Its main business is LED display screen manufacturing business, digital marketing business and outdoor advertising business.

\subsubsection{Profile of the Acquired Party}

The continuous M\&A of Lianjian Optoelectronics involves many enterprises. This paper only takes two representative enterprises as a case study.

Sichuan time-sharing Advertising Media Co., Ltd (hereinafter referred to as "time-sharing Media") was established in 2006 by Chengdu Dayu Weiye Advertising Co., Ltd and natural person he Jilun. The largest shareholder of time-sharing 
media is natural person he Jilun contribution accounts of $57.268 \%$.

Shenzhen Precision focus Media Co., Ltd (hereinafter referred to as "Precision focus") was established by the legal representative Ying Ping in July 2012, with a registered capital of 3 million yuan. The company's business scope includes advertising business, import and export trade, information consulting, computer hardware and software technology development and sales.

\subsection{M\&A Performance Commitments and Compliance}

\subsubsection{Time Media Performance Commitment Agreement}

According to the profit forecast compensation agreement signed by Lianjian Optoelectronics and Time-sharing Media, Timesharing Media promises net profit of no less than 87 million in 2013, 100 million in 2014, 113 million in 2015, 122 million in 2016 and 128 million in 2017. The agreement promises that if the net profit realized in each year of the five-year period does not meet the agreed net profit, then the time-sharing media should according to the agreement to build the photoelectric rights and interests compensation, And according to the following formula to determine the amount of compensation for the current year:

The amount of compensation payable for the current year $=$ (cumulative net profit at the end of the current period-accumulative net profit at the end of the current period) $\div$ the sum of the net profit promised for each year of the commitment period $x$ the number of shares compensated for the value of the underlying assets

Table 1. Achievement of media performance commitments 2013-2017

\subsubsection{Performance Commitment Agreements for Precision Focus}

According to the agreement signed by Lianjian Optoelectronics and Precision focus, Lianjian Optoelectronics's acquisition of Precision focus is paid in instalments in the year of signing, according to quarterly profit completion, while Precision focus promises that the company will actually achieve net profit of no less than 20 million yuan, 30 million yuan and 40 million yuan in 2015, 2016 and 2017, respectively. If the net profit is not agreed upon in each year of the three-year period, the accurate focus shall be paid to Lianjian Optoelectronics in cash according to the following formula:

The amount of compensation payable for the current year $=$ (cumulative net profit at the end of the current period-accumulative net profit at the end of the current period) $\div$ the sum of the net profit promised for each year of the commitment period $\times 100 \%$ equity price of the company-compensated cash

\subsubsection{Achievement of Performance Commitments}

In the M\&A transaction between Lianjian Optoelectronics and time-sharing Media, the actual performance of time-sharing Media cannot reach the agreed target, and the concrete commitment is shown in "Table 1". Time-sharing media only completed the promised net profit in the first year of the commitment period (2013) and did not complete the commitment for the next four years.

\begin{tabular}{|c|c|c|c|c|}
\hline $\begin{array}{r}\text { commitmen } \\
\text { perioc }\end{array}$ & $\begin{array}{r}\text { commitment } \\
\text { net profit }\end{array}$ & $\begin{array}{r}\text { actual } \\
\text { net profit }\end{array}$ & ifference & $\begin{array}{r}\text { percentage } \\
\text { complete }\end{array}$ \\
\hline & $\begin{array}{r}\text { Im } \\
\text { Inflows/ } \\
\text { (Outflows) }\end{array}$ & $\begin{array}{r}\text { ¥m } \\
\text { Inflows/ } \\
\text { (Outflows) }\end{array}$ & $\begin{array}{l}\text { Im } \\
\text { Inflows/ } \\
\text { Dutflows) }\end{array}$ & \\
\hline 2013 & 87.00 & 90.31 & 3.11 & $103.81 \%$ \\
\hline 2014 & 100.00 & 95.79 & $(4.20)$ & $95.79 \%$ \\
\hline 2015 & 113.00 & 75.08 & (37.91) & $66.45 \%$ \\
\hline 2016 & 122.00 & 99.04 & (22.95) & $81.19 \%$ \\
\hline 2017 & 128.00 & 72.82 & $(55.17)$ & $56.89 \%$ \\
\hline
\end{tabular}


In the merger and acquisition of Lianjian Optoelectronics and Precision focus, the agreement agreed that the net profit for 2015-2017 should reach 20 million yuan, 30 million yuan and 40 million yuan respectively. However, the actual amount of precision focus achieved was only up to 2015, and the remaining two years of difference failed to reach the commitment level. The performance commitments are achieved as shown in "Table 2":

Table 2. Achievement of performance commitments by precision focus 2015-2017

\begin{tabular}{|rrrrr|}
\hline $\begin{array}{r}\text { commitment commitment } \\
\text { period } \\
\text { net profit }\end{array}$ & $\begin{array}{r}\text { actual } \\
\text { net profit }\end{array}$ & difference & $\begin{array}{r}\text { percentage } \\
\text { complete }\end{array}$ \\
\hline & $\begin{array}{r}\text { Inflows/ } \\
\text { (Outflows) }\end{array}$ & $\begin{array}{r}\text { Inflows/ } \\
\text { (Outflows) }\end{array}$ & $\begin{array}{r}\mathbf{¥ m} \\
\text { Inflows/ }\end{array}$ & \\
(Outflows) & \\
\hline $\mathbf{2 0 1 5}$ & 20.00 & 22.99 & 2.99 & $114.95 \%$ \\
$\mathbf{2 0 1 6}$ & 30.00 & 24.84 & $(5.16)$ & $82.81 \%$ \\
$\mathbf{2 0 1 7}$ & 40.00 & 32.70 & $(7.30)$ & $81.76 \%$ \\
\hline
\end{tabular}

a Source: Lianjian Optoelectronics special audit report on the achievement of accurate focus profit forecast

Final precision focus original shareholders to the M\&A - Lianjian Optoelectronic subsidiary linkage investment compensation amount of 28.3904 million yuan. According to the final information disclosed in the announcement, as of April 2018, the original shareholders of precision focus had a total of 4024355 shares of the company's shares pledged to the linkage investment.

\subsection{Performance Analysis of Continuous M\&A of Lianjian Optoelectronics}

M\&A performance analysis usually establishes an index system from five aspects: core competitiveness, profitability, solvency, main business situation and asset management ability.

\subsubsection{Scale Analysis}

Lianjian Optoelectronics has adopted continuous M\&A to achieve rapid expansion since 2013. The company's business scope has expanded from LED sales and outdoor advertising business to brand public relations services, outdoor media networks and digital advertising equipment as its core business.

In the field of network advertising agency business, the subsidiary Lima Network, as an Internet advertising agent, has rich operational ability and sufficient competitiveness in the same industry. In recent years, it has gradually become the top 10 core agents in Tencent. On the other hand, the company completed the acquisition of new media, using its cloud Rubik's Cube advertising resource platform, and integrating a large number of customer resource data from both sides, synthesizing outdoor media advertising and online brand advertising in advertising form. Speed up its expansion and acquisition of enterprises to form synergy, establish complementary benefits.

\subsubsection{Financial Analysis}

\subsubsection{Analysis of Profitability}

In order to study the long-term and short-term impact of the performance commitment of continuous M\&A on the profitability of enterprises, this paper selects two kinds of profit level indicators during and after the performance commitment period of M\&A in 2013-2019 to analyze and study. Specific indicators are shown in "Figure 2". 


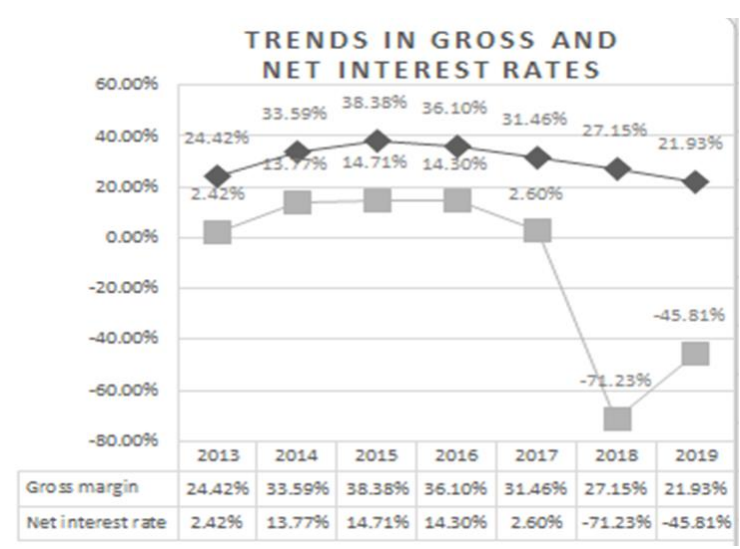

Figure 2 Gross and net interest rate trend chart for 2013-2019.

By comparing and analyzing the gross profit rate and net interest rate trend of Lianjian Optoelectronics over the years, it can be found that in the initial period of the company's rapid expansion strategy (2013-2015) both gross profit margin and net interest rate increased significantly. By comparing the time node, it is found that 2014 and 2015 are the starting point of the performance commitment period for most enterprises in the continuous M\&A, and the first period of performance commitment is often reached or even exceeded. However, this performance improvement is often short-term and unsustainable.

After the initial period of rapid expansion, the profit growth level of Lianjian Optoelectronics slowed or began to decline in 2016-2017. This phenomenon is also reflected in two profit indicators, indicating that enterprises suffer

Table 3. Current ratio and asset-liability ratio of Lianjian Optoelectronics 2013-2019

\begin{tabular}{|lrrrrrrr|}
\hline & 2013 & 2014 & 2015 & 2016 & 2017 & 2018 & 2019 \\
\hline liquidity ratio & 1.99 & 2.19 & 2.1 & 1.03 & 0.91 & 0.84 & 0.77 \\
YOY basis & & $10.05 \%$ & $-4.11 \%$ & $-50.95 \%$ & $-11.65 \%$ & $-7.69 \%$ & $-8.33 \%$ \\
\hline asset-liability ratio & $37.95 \%$ & $23.67 \%$ & $19.07 \%$ & $27.91 \%$ & $41.14 \%$ & $57.01 \%$ & $79.94 \%$ \\
YOY basis & & $-37.63 \%$ & $-19.43 \%$ & $46.36 \%$ & $47.40 \%$ & $38.58 \%$ & $40.22 \%$ \\
\hline
\end{tabular}

As can be seen from "Table 3", the assets and liabilities structure of the company has been steadily optimized during the period 2013-2015, the current ratio has risen slightly above 2 . The current assets and liabilities structure of the company is stable and short-term debt repayment is fully guaranteed. subsequent profitability, gross profit rate decline and the company enhancement through M\&A expansion has not been achieved. Therefore, from the aspect of profitability, it can be concluded that the performance commitment agreement of continuous M\&A can indeed bring outstanding performance improvement in the short term, but ineffectiveness in the long run.

\subsubsection{Solvency Analysis}

In order to study the solvency of Lianjian Optoelectronics after continuous M\&A, this paper adopts the indicators of short-term solvency and long-term solvency and selects the assets and liabilities data of the company for the period 20132019 to analyze. The specific data are shown in "Table 3".
Since 2016, the two ratios have simultaneously changed in opposite directions. As the range of change is approaching, it can be intuitively inferred that the large probability of the change comes from current assets and liabilities. According to the company's 2016 annual report, the main reason for the change is the sharp increase in short-term borrowing and other accounts payable in current 
liabilities. Combined with the company's cash flow, it can be judged that the main purpose of short-term borrowing is the cash expenditure of a continuous M\&A company. Although the company uses a dual payment structure of cash and issued shares, it still cannot avoid the huge demand for cash expenditure.

Three years after the continuous M\&A period, until 2019, the company's assets and liabilities have remained unchanged. From the trend of short-term and short-term indicators, it can be found that the current ratio is still falling, but the declination is gradually lowering.

The performance commitment agreement does not play an expected role in the solvency of the enterprise. The indemnity clause set up by the agreement to protect the interests of the investor has drawbacks in practical application. The lack of ability to repay compensation and performance commitment agreement cannot be effectively implemented which ultimately cannot protect the interests of investors.

\subsubsection{Growth Ability Analysis}

In order to study the growth ability of Lianjian Optoelectronics, this paper adopts two core indexes of operating income and net profit, and selects the income and profit data of the company in 20132019 to analyze; the specific data are shown in "Table 4".

Table 4. Operating income and net profit for 2013-2019

\begin{tabular}{|c|c|c|c|c|c|c|c|}
\hline & 2013 & 2014 & 2015 & 2016 & 2017 & 2018 & 2019 \\
\hline & Im & $¥ \mathrm{~m}$ & Im & $\pm \mathrm{m}$ & ¥m & $\pm m$ & $\mp \mathrm{m}$ \\
\hline & $\begin{array}{r}\text { Inflows/ } \\
\text { (Outflows) }\end{array}$ & $\begin{array}{r}\text { Inflows/ } \\
\text { (Outflows) }\end{array}$ & $\begin{array}{r}\text { Inflows/ } \\
\text { (Outflows) }\end{array}$ & $\begin{array}{r}\text { Inflows/ } \\
\text { (Outflows) }\end{array}$ & $\begin{array}{r}\text { Inflows/ } \\
\text { (Outflows) }\end{array}$ & $\begin{array}{r}\text { Inflows/ } \\
\text { (Outflows) }\end{array}$ & $\begin{array}{r}\text { Inflows } \\
\text { (Outflows) }\end{array}$ \\
\hline operating inco & 585.61 & 970.10 & $1,522.59$ & $2,775.45$ & $3,952.36$ & $4,053.37$ & $3,013.56$ \\
\hline YOY basis & & $65.66 \%$ & $56.95 \%$ & $82.28 \%$ & $42.40 \%$ & $2.56 \%$ & $-25.65 \%$ \\
\hline & 16.27 & 133.97 & 223.67 & 258.61 & 104.28 & (2888.17) & $(1381.10$ \\
\hline OY basis & & $723.42 \%$ & $66.96 \%$ & $15.62 \%$ & $-59.68 \%$ & $-2869.63 \%$ & $-52.18^{\circ}$ \\
\hline
\end{tabular}

Source: JIAO 2013-2019 annual report

Under the influence of continuous M\&A, more than half of the M\&A or acquisition enterprises' performance commitment period is concentrated in 2013-2017. Due to the incentive effect of performance commitment, the company's operating income has maintained a high growth rate during this period, with an average annual growth rate of more than 50. Net profit changes are similar. Until 2017 , the growth rate of subsidiaries began to slow down, and the operating conditions of many M\&A subsidiaries began to deteriorate. In addition, the introduction of new policies made the company have to calculate a large amount of goodwill impairment, thus causing a sharp decline in net profit causing the profit growth rate back to the negatives. After the explosive growth of the subsidiary company during the performance commitment period, the development stamina is insufficient, and the operating income of the sustained high growth rate cannot be maintained for a long time.

\section{CONCLUSIONS AND RECOMMENDATIONS}

\subsection{Conclusions}

Based on the existing literature and theoretical research results of continuous M\&A and performance commitment, this paper analyzes the impact of performance commitment agreement on long-term and short-term performance of the company, and finally draws the following conclusions:

- Performance commitment agreement will lead to long-term performance risks. Performance commitment can stimulate the M\&A enterprise, but premium payment brings a high level of commitment performance. In the face of highperformance commitment, M\&A is likely to make short-term business behavior that ignores long-term profits and focuses on short-term gains. This is contrary to the company's long-term strategic objectives. Ultimately, the strategic objectives of continuous mergers and acquisitions are difficult to achieve, as performance is characterized by a sustained and 
irreversible decline after short-term growth.

- Different compensation methods have different effects on $\mathrm{M} \& \mathrm{~A}$ risks. The use of cash compensation will lead to greater cash flow risk in M\&A. Once the enterprise needs to pay cash compensation according to the agreement, it will greatly increase the short-term cash outflow of the enterprise, and then affect the subsequent performance and development of the enterprise. The use of equity compensation can avoid short-term cash outflow, but it will lead to the actual payment of compensation by the buyer higher than the unrealized profit difference.

\subsection{Recommendations}

\subsubsection{Rational Evaluation of Enterprise Value}

In order to avoid such risks, M\&A can only specify a higher standard of performance appraisal on the performance commitment, which leads to the high risk under the high premium payment. Only a reasonable assessment of the value of the enterprise can determine the actual value of M\&A and specify more reasonable performance commitment criteria, so the M\&A party should strive to achieve the following:

- Careful select appropriate and reliable evaluation agencies and pay attention to due diligence before $M \& A$, use professional third-party evaluation agencies to conduct a comprehensive evaluation of the M\&A party, and understand the real asset information of the underlying enterprise as far as possible in the asymmetric information environment. This not only helps to reduce M\&A costs but also estimates the real business situation and future growth space.

- The situation of the M\&A is clear; the change of the industry situation will greatly affect the strategic objectives and profitability of the enterprise. M\&A should fully understand the future business situation of its industry and the changes of related competitors.

\subsubsection{Improved Performance Commitment Agreement}

The original design purpose of the performance commitment agreement is the same as "contingent consideration" - to encourage the M\&A to maintain its original development momentum. After adding the performance compensation clause, the protective effect on the buyer gradually becomes a profit-making means.

To perfect the performance commitment agreement, we need to know enough business and asset information through due diligence before M\&A and to design a reasonable performance commitment amount. To avoid affecting the development ability of the buyer, we should avoid using cash compensation as much as possible and use more equity compensation or "cash + equity" compensation. Let the performance commitment agreement return to the nature of the initial deferred payment, rather than the exit mechanism of the agreed compensation.

\section{AUTHORS' CONTRIBUTIONS}

Liangchen Zhang is responsible for writing the manuscript and analysing data, $\mathrm{Yu} \mathrm{Wu}$ contributed to revising and editing, and Chao Chen is responsible for data collection.

\section{REFERENCES}

[1] Chaoyun Du. Yilei Chen. [J]. Performance Commitment, Corporate M\&A and Performance Improvement Economic community. 2020(04): 65-70

[2] Yuhang Wang. Qi Zhou. Application of Gambling Agreement in the M\&A of Internet Game Enterprises [J]. 1 Cooperative economy and science and technology. 2020(13): 94-97

[3] Xizhu Zhang. A Risk Analysis of M\&A Based on Performance Commitment in the Context of Continuous M\&A: A Case Study of Sanno Biological [D]. Guangdong University of Foreign Studies. 2020

[4] Jiaxin Li. Study on the Risk of Gambling Agreement Based on the Protection of the Interests of Small and Medium-sized Shareholders - Taking Huayi M\&A Dongyang as an example [J]. 1 Prices in China. 2020(12): 66-68

[5] Yunbao Zhang. Shaofu Li. How to Reduce M\&A Risk [J]. Journal of Enterprises Guangxi quality Supervision Guide. 2020(09): 205-206

[6] Chuanli Zhou. Path Dependence on Private Equity Financing, Gambling Agreement and 
Financial Performance of Growth Enterprises [J]. (Agencies Academic research. 2009(03): 89-93

[7] Ninon Kohers, James S. Ang. Earnouts in Mergers: Agreeing to Disagree and Agreeing to Stay [G]. 2000 The Journal of Business. Volume: 73, Issue: 3,445-476

[8] Christian Tallau. The Value of Earn-out Clauses: An Option-based Approach [J]. 2009Business Valuation Review. Volume: 28, Issue: $4,174-180$

[9] Reena Kohli. Financing strategies and shareholders' risk in cross border acquisitions in India [G]. 2015 International Journal of Commerce and Management. Volume: 25, Issue: 3,294-308 